\section{LLIÇÓ DE COMIAT (ETSAB, 23 DE MAIG DE 1996)}

\section{Manuel RIBAS PIERA}

Benvolguts tots, amigues i amics:

En una circumstància com aquesta, és molt important saber trobar el to en què he d'expressar-me. Mentre preparava la meva intervenció he estat pensant en la possibilitat de seguir diferents "models":

1. El primer seria acollir-me a la línia llagrimosa, fent un recordatori dels 40 anys que he estat vinculat a aquest Centre, des del mes de febrer de 1956, en què vaig guanyar les oposicions de professor auxiliar en l'àrea de Projectes i de Composició.

2. Seguint a la baixa, també podria preparar una lliçó paternalista i emotiva amb abundància de consells als actuals professors i alumnes, a partir de l'experiència viscuda.

3. Podria ser encara una lliçó "pinyol", com si avui tornés a opositar a la Càtedra que he deixat.

Cap de les tres no m'agrada:

1. La primera, ja l'explicaré el dia en què escrigui les meves Memòries.

2. La segona, constituirà l'emocionant pròleg i colofó de les esmentades Memòries.

3. Pel que fa a l'intent de la tercera via, penso que si de cas, tornaria a explicar la mateixa lliçó d'oposicions, que prou bé que em va anar; però, voleu dir...?

Finalment, he triat un altre model: ja que tots veieu en mi el passat, us he de portar la contraria i parlar del futur; del futur de l'Urbanisme, és clar.

Fent la paròdia, evidentment respectuosa, d'un famós diàleg, ara he de preguntar: i què és l'Urbanisme?

Tot i que, al final, he de negar el mateix nom d'Urbanisme, almenys per començar vull aclarir de quin Urbanisme parlo.

Hi ha un Urbanisme científic que no fa més que reflexionar sobre la Ciutat i el Territori. És molt, però pot ser poc.

Hi ha un altre Urbanisme-planificació, que actua amb immediateses $\mathrm{i}$ intuïcions. Però no em refio dels que nomes són intuïtius. Prefereixo referir-me a l'Urbanisme "total" o "global" com ara es diu: Urbanisme és un conjunt de coneixement teòrics que cal aplicar en forma de Pla per a organitzar eficaçment el territori.
Permeteu-me un breu recordatori per als qui no són urbanistes. Urbanisme no és ni l'art de fer ciutats ni la tècnica de fer-les més visibles i viables.

Fer Urbanisme ja és i continuarà essent gairebé una manera de ser i d'actuar, la mirada de qui és capaç, només amb la vista i l'anàlisi mental, de llegir una estructura territorial; i ,després, de construir el procés, bé sigui l'estratègia de projecte o de pla, ara no és el moment per a aquesta discussió, important però que ve després. Procés i estratègia per a aconsellar com cal incidir sobre aquella estructura entrevista, per tal de fer-la harmònica i equilibrada.

L'estètica vindrà més tard.

Així doncs, fer Urbanisme és i serà aconsellar amb fonaments. Si es tracta d'un $\mathrm{Pla}$, el destinatari del consell és i serà el grup social; en el projecte serà el directo d'obra l'aconsellat. Hi ha doncs un esglaonament categòric mesurat per la transcendència del consell que dóna l'Urbanista (llegiu-hi Pla).

Això em dóna entrada a la primera part de la meva lliçó d'avui sobre el futur de l'Urbanisme.

Posat a fer en el difícil camp de la prospectiva, per bé que sigui aplicada a una matèria que conec bé, només veig clar que pugui endinsar-m’hi per dos camins diferents, d'acord amb la distinció que acabo de fer entre Ciència de l'Urbanisme o Teoria del poblament, i Política urbanística o Teoria de Plans.

No és que vulgui contradir el que acabo d'afirmar sobre la indivisible unitat d'ambdós aspectes. Ho són.

Però ara es tracta d'explicar-vos alguns aspectes del que jo crec que ha de ser això que encara en direm Urbanisme i que probablement deixarà de dir-se'n (perquè el nom actual serà rebutjat per reduccionista. En parlaré).

Veig dos aspectes en els que vull centrar-me. Responen a les preguntes:

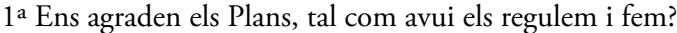

I, si no ens agraden -i en un inici que hem viscut, sí que ens agradaven-, hem de canviar-los?

$2^{\mathrm{a}}$ Anant més lluny: tenim clares les múltiples denominacions amb què ens referim a la construcció de l'entorn, arquitectura, disseny urbà, planejamen urbà, ordenació territorial, arquitectura del paisatge, paisatgisme? Crec que la confusió és més profunda que un mer i superficial nominalisme (que no faria mal a ningú), sinó que és realment perjudicial perquè mai són bons el coneixements fragmentats, i perquè l'actual sospita d'un camp unitari un dia es pot fer realitat. Els reptes són difícils però semblen apassionants.

Que no m'hagueu de perdonar més tard la imprudència d'endinsar-m'hi, és el desig que em guia i em fa prosseguir. 


\section{Apartat Primer, sobre el futur del planejament urbanístic.}

És el passat qui configura, ni que sigui de lluny, el futur que vindrà. Fixem-nos en allò tan conegut de la manera com la Teoria de Plans s'ha anat allunyant cada vegada més del criteri de certesa: primer, plans optimitzadors; després, plans aproximatius, per acabar en plans -o bons consells-, simplement probabilístics. Quan un procés similar ha passat amb una cosa tan seriosa com ara la Física, quan avui els parlen d'un futur de Física Estadística, que vol dir simplement probabilista, no ha de passar i més amb l'Urbanisme, que té un peu ferm sobre les Ciències Socials, les que mai no han sigut ni poden ser mai deterministes?

Quin descans si podem alliberar-nos del Pla tapaforats, el qual pretesament ho resol tot i del qual ningú no se n'escapa: i així podrem anar cap a un Pla indicatiu de consells, seriosos, estrictes i ben formats, probabilístic al cap i a la fi!

Si encara això no us convenç, penseu: quin sentit té pensar en to apocalíptic que cal continuar fent Plans perquè les Ciutats canviïn? Creieu que les èpoques fundacionals poden repetir-se cada vint anys? Un dia vaig escriure: només una guerra, una catàstrofe pot fer canviar una Ciutat!

Què és el que em mou a predir aquest futur? En primer lloc, i no ho nego, una visió optimista del progrés. (Deixeu-me posar un exemple d'actualitat: el cas recent del camp de l'Espanyol a Sarrià. No ha estat la rigidesa del Pla vigent la que ha frenat el primer assalt, sinó la consciència ciutadana que ja sap què vol dir "urbanitat" i ho ha après a Barcelona a partir dels anys vuitanta).

Recordo una experiència col-lectiva a la que he donat sempre un gran valor testimonial. Durant la redacció del que després va ser l'Esquema Director de 1968 (acabat el 1965), un grup tendencial varem oposar-nos a la rigidesa del "zoning" i en un desfici utopista vàrem dibuixar un plànol "puntillista", és a dir que -no tenia colors-zones- llisos, sinó dominància de zona segons la densitat dels punts de color. El color del segle xxi que ara m'ocupa ja despuntava a la tan creativa, per tants motius, dècada dels seixanta.

Jo crec sincerament que la planificació urbanística no pot continuar així, i quan les coses no poden continuar, no saps com però a la fi canvien.

Vegem què passa avui dia amb els grans Plans:

a. O bé les autoritats amb poder econòmic no se'l prenen seriosament (com esta passant, em sembla, amb el PIa Territorial de Catalunya);

b. O bé cal signar prèviament tal quantitat de compromisos previs que el valor normatiu del Pla esdevé, com he dit, només probabilístic, però no d'acord amb el bé públic com tots defensaríem, sinó en virtut dels compromisos adquirits.

És el cas de molts Plans estratègics amb els quals hom assegura el fer, i fins i tot el com fer-ho, però no el com serà; c. O bé, per evitar solucions irresolubles, cal mantenir la carcassa d'un vell Pla i anar-lo sargint i apedaçant quan calgui. (És el cas del PGM, amb més de mil modificacions puntuals en vint anys, és a dir, gairebé una modificació puntual per cada setmana que passa).

Aquestes tres maneres de fer abonen la meva predicció pera una nova manera de fer Urbanisme. Però és més, hi ha encara dues presumpcions que condueixen al mateix camí.

La primera és la tendència des de fa uns quinze anys a anar vers l'Urbanisme concertat. Això, que trenta anys enrere hauria estat objecte de rebuig escandalitzat i fins i tot de condemna a qui s'atrevís a suggerir-ho, és avui, en bastants casos, una via de sortida cap el realisme. L'Urbanisme-negoci, segon frase que vaig sentir un dia a un destacat urbanista espanyol i que no escandalitzava ningú, és una porta cap al relativisme que preconitzo. Però, compte! L'Urbanisme-negoci no vol dir primordialment "Urbanisme-com-a-negoci", sinó Urbanisme amb el qual el privat també hi guanya, sense minva del benefici públic

Quina altra cosa no volen ser les concessions d'autopistes i fins i tot, quina és la mentalitat de "Barcelona Regional", sinó aquesta?

La segona presumpció de futur, molt pròxima a aquesta tendència, és la generalització de les accions concertades refoses en el si dels plans estratègics. Jo hi crec, en els plans estratègics, però només si són programes recolzats en un $\mathrm{Pla}$ urbanístic que prèviament hagi considerat les accions que cal emprendre segons els recursos territorials, de llur mantenibilitat o conservació, i en conseqüència del benestar de llurs habitants, presents i futurs.

Tant els plans estratègics com els contractes-programa són garanties de factibilitat però també ferides obertes a la fortalesa del Pla racional.

Per tant, són arguments a favor de l'arribada d'un planejament simplement satisfactori i probabilístic que he anunciat més amunt.

En rellegir el que he dit fins ara, m'adono d'una possible interpretació que no és la pretesa. Algú pot comentar que faig la defensa d'una mena de neo-liberalisme aplicat al planejament. No sé ben bé què voldria dir neo-liberalisme, però si sé què he volgut dir fins ara.

Tots tenim massa ficats al cap l'Ordenança, la Zonificació i sobretot el temor a l'abús, bé sigui d'un particular sense civisme o d'una administració facilment seduïble. Jo pretenc fixar un guió que recolzi, com ja he dit, en un autèntic i no-escrit control social de part dels ciutadans als quals poden afectar les mesures.

Jo parteixo de la possibilitat de gestionar plans mitjançant programes prèviament pensats i després convinguts amb els promotors interessats. 
Jo parteixo, encara, del valor irradiant -i tant que n'hem parlat!- de l'arquitectura que construeix les nostres ciutats i els nostres paisatges, i de com il.lumina i programa per sí mateixa el que ha de passar al seu entorn.

En definitiva, crec que el futur del Planejament urbanístic i territorial cristal-litzarà en Plans globals, però concrets i finalistes, oberts i estimulants per a les iniciatives de gestió que sorgeixin, fins i tot si són privades. Deixarem de pensar, -quina sort!-, en la igualtat privat = insolidari. És així com heu d'interpretar aquesta aventurada predicció.

\section{Apartat segon, sobre el futur de la Construcció de I'Entorn.}

Entrant a la segona de les prospeccions anunciades, començo com abans pe fer una visió crítica de com ha anat canviant, en els darrers temps, la manera d'entendre el Territori.

Primera constatació: cal que arribi, 1910, el concepte d'Urbanisme perquè ens adonem dels efectes territorials de l'Arquitectura. Avui ningú no en dubta.

L'Urbanisme "dur" dels primers tractadistes del XIX (Cerdà i la seva Teoria general, Stübben i el seu Stadtebau) s'assembla, salvant totes les distàncies, als utopistes del primer Renaixement, tots ells més sociòlegs, com diríem avui, que no pas constructors. Em refereix-ho al Filarete, a Martini, al frare Campanella i a canceller Thomas More. Quina diferencia hi ha entre els seus esquemes, quan algun d'ells arriba a dibuixar-se, de les Ciutats ideals que vindran més tard, és a dir, la de Vasari el jove i la d'Ammanati!. Molt abans que Rossi i els rossians, brota en aquells la noció i el repertori de tipus edilicis, però sempre en esquema.

És clar que els tractadistes de l'Urbanisme "dur" aviat són succeïts per l'Urbanisme "suau" de Soria i Mata, d'Unwin i sobretot de Sitte. Els primers foren urbanistes sense arquitectura, els segons són arquitectes que fan ciutat. I des d'ara, aquesta serà la tendència constant. Personalment, quan utilitzo alguna d'aquestes frases, "el valor irradiant de l'arquitectura i en particular dels equipaments o sistemes" o bé "la ciutat està feta d'arquitectures i l'arquitectura és la que fa la ciutat", expresso aquesta convicció.

Per què ho dic? perquè la unicitat d'Urbanisme i Arquitectura es comença a fe palesa. Durant uns anys en que amb en Jordi Carbonell vaig portar el Taller d'Urbanisme en aquesta Escola, recordo que feia un curset titulat "Com es fa Urbanisme, sovint sense saber-ho, des de l'Arquitectura" i explicava quatre vies que vaig explorar aleshores i que no és del cas repetir aquí.

Però sí que el descobriment (nascut arran del PFC d'Urbanisme, tan controvertit sempre) és una fita que deixo posada en el camí de la meva argumentació.

Segona constatació, que derivo de la moderna rebel-lió contra l'Urbanisme dels estàndards i de les teories socials quantitatives; vers la consecució de la qualita urbana que fins ara promet, però no assegura, l'Urbanisme dels Plans generals.
Afirmo, si fa no fa, una sentència molt semblant a la que acabo de constatar amb la frase "la Ciutat està feta d'arquitectures i l'arquitectura és la que fa la Ciutat". Reconec com a inici de la revolta un per a mi famós pròleg d'Oriol Bohigas a "Plans i projectes...", que marca l'arrencada de l'anomenada, -potser massa emfaticament-, "dècada miraculosa", és a dir, la dels anys 80 .

En aquesta rebel-lió o revolta, que -deixeu-m'ho dir- és totalment irreversible, comencem a acostar-nos a un altre concepte que m'interessen ressaltar, en la meva dèria per a provar la unicitat de la Construcció de I'Entorn. Em refereixo al paisatge $\mathrm{i}$, en aquest cas que estic constatant, al paisatge urbà

L'Urbanisme qualitatiu es refereix, òbviament, també a la qualitat de l'arquitectura que el compon, però més directament al paisatge urbà. Recordem que paisatge és el sumatori no algebraic de totes les sensacions que un espectador rep procedents de l'entorn. Si és espectador fix serà un paisatge pictòric, tal com el paisatgisme va néixer; si, en canvi, és espectador mòbil, serà un paisatge seqüencial cinematogràfic, tal com molts de vosaltres m'heu sentit explicar en els cursos que feia.

La qualitat que propugna l'Urbanisme "qualitatiu" és de paisatge, i per aquí estem ja llençant ponts entre Urbanisme i Paisatgisme, tal com us havia iniciat a fer-ho entre Urbanisme i Arquitectura. Aviat intentaré treure'n conclusions.

Tercera constatació, que fa referència a les conseqüències del progressiu interès pel Territori en tots els àmbits del Disseny. Durant molts anys, al llenguatg professional de l'Urbanisme Territori era sinònim de No-ciutat. En els temps que acabem ara de coronar, només ha interessat la Ciutat i molt poc el Territori, com es demostra pel poquíssim interès que, en general, atorguen els Plans vigents als espais no edificats. Denominacions genèriques com ara sòl no urbanitzable, espais rústics o forestals, sòls de reserva, etc., ho palesen.

Hi ha hagut, però, episodis d'aquesta segona meitat del segle xx que han posat, potser inconscientment, les bases pera una nova comprensió dels espais esmentats, per a que deixessin de ser espais residuals i de simple acompanyament i esdevinguessin protagonistes al mateix nivell que la ciutat contínuament edificada.

Un dels primers fou la teoria de les Àrees Metropolitanes que alguns van anomenar de la Ciutat-Territori i encara de la Ciutat-regió. En aquesta hom definia per primera vegada conceptes abans esmentats, com ara accessibilitat sense contigüitat, ciutat difusa, ciutat discontínuament edificada, ciutat multi-polar o descentrada, perifêries urbanes, espais intersticials, etc. És facil veure com tots aquests nous conceptes portaven l'atenció cap al Territori com a entitat globalitzadora en el si de la qual els nuclis edificats eren importants accidents, però no els únics.

Un altre episodi, aquest de signe pràctic, evident i viu encara, és el de la nova cultura de l'oci i els conseqüents camps d'influència urbana vacacional, és a dir, ociosa, que es manifesten progressivament cada cap de setmana i encara més durant els períodes de vacances tradicionals (Nadal, Setmana Santa i alguns famosos 
“ponts'). Em refereixo a l'èxode temporal dels ciutadans vers el Camp i la Natura, que exigeix portar les normes i els mètodes urbanístics sobre els territoris amb amenaça de colonització desordenada, ciutat temporal per a la satisfacció de l'oci massiu. El planejament d'aquestes àrees d'ús ociós, que poden ser tan o més extenses que tota una ciutat, -per més que amb pautes d'ús i estructura funcional ben diferents-, són també una entrada precursora per a començar a considerar el Territori com a subjecte positiu i no pas merament passiu: és el descobriment del Paisatge per part de tots els consumidors de Paisatges com a lleure de masses.

Hi ha encara un altre episodi, coadjuvant a aquesta tercera constatació, d'àmbit mundial, que encamina l'interès vers l'espai no edificat. És l'anomenat ecologisme o naturalisme, avui perfeccionat amb la crida al desenvolupament mantenible o durable. Des de la Conferència mundial de l'any 1974 a Estocolm, fins a la cimera de Rio de 1991, passant pel programa de les Nacions Unides "Man and Biosphere" -i el que pugui venir-, es pot dir que la consciència de la Humanitat per a mantenir l'ús racional dels recursos de la Terra està encarrilant l'atenció vers un territori global en que Entorn o Environment és la nova paraula que cal tenir present a l'hora de fer Urbanisme.

Els tres "episodis" esmentats són, cadascun, prou forts per a pensar que cal emmarcar l'Urbanisme que esta venint en unes coordenades clarament territorials i no pas merament urbanes en el sentit de la ciutat tradicional.

L'interès pel Territori ha reforçat, en el camp de l'Urbanisme, la pluridisciplinarietat que ara ja és una característica plenament assumida a l'hora de fer Planejament. D'una banda, hi participen les professions normatives com ara els enginyers (d'obres públiques, d'agronomia, forestals), els economistes i el advocats; de l'altra, les professions descriptives com ara geògrafs, sociòlegs i naturalistes.

Una altra conseqüència de l'interès pel Territori es fa palesa en la major importància que dins de la Cultura dels Plans han adquirit els planejaments supramunicipals. En tots ells predomina la No-ciutat, moltes vegades perquè els nuclis ja estaven ordenats en un planejament de rang inferior, municipal.

Així doncs, i per concloure, cal reconèixer que a les darreries del segle xx, just al tombant del segle, hem adquirit consciència del "sistema total" que és el Territori, i que de passada posa l'accent sobre el Paisatge com a morfologia concreta de l'anomenat Environment o Entorn.

I també que el Territori és un tot, sigui edificat o no, sigui humanitzat o no, sigui "natural" o no. És a dir, que dins del Territori hi ha les Ciutats i que aquestes no són una excepció o una illa que cal tractar a part. Afirmar el contrari seria caure en un narcisisme urbanístic, com ho seria l'altre extrem, negar que en aquest complex conjunt territorial la ciutat continua essent el motor principal i la seu -ara per ara-de les majors concentracions humanes.

\section{Conclusió. El viratge al Paisatgisme.}

Paisatgisme és encara, per a molts, una nova paraula que amplia el tradicional Art dels jardins vers una major escala; poc o molt, tal com l'abordaren els jardiners anglesos en arribar la segona meitat del segle XviII.

Certament, la introducció de l'interès pel Paisatgisme arrenca del camp de la Pintura i es fa realitat física amb els constructors de parcs privats que esdevenen dissenyadors del Paisatge.

Ningú no pot negar a aquests fets el paper de precursors, però ningú no els pot atribuir valor de fet social i generalitzat; sinó tot el contrari, de marcat caràcter aristocràtic i per tant minoritari. Llur indubtable valor com a fet artístic no va implicar cap influència massiva.

Des d'aleshores es pot parlar als països anglosaxons i nòrdics d'una línia de constructors de paisatges (paisatgistes) que en començar el segle xx estrenen la denominació d' "arquitectes del Paisatge", a partir de la qual estructuren una professió i també una acadèmia a gairebé totes les Universitats dels països abans esmentats.

Hom pot dir que en els països llatins el procés no s'ha donat, per ara.

A les vores del Mediterrani és encara l'arquitecte qui, si cal, estableix les convingudes incursions en el camp de la Construcció global de l'Entorn.

Enfront de l'actual paral-lelisme entre arquitectes del Paisatge i arquitectes, es pot recordar com el gran impuls de la Teoria urbana i del Planejament urbà durant la dècada dels seixanta planteja una situació similar de paral-lelisme entre els aleshores arquitectes i els urbanistes. Els arquitectes del Sud d'Europ no varen crear, en general, una nova professió i una nova acadèmia, sinó que alguns anunciaren l'extensió de l'Arquitectura al camp de l'Urbanisme i, en un procés descendent que immediatament es produí, del Disseny urbà a l'Arquitectura de la Ciutat. D'això en dona bon testimoni la Barcelona dels anys 80 com ja he dit abans.

En els països del Nord d'Europa i d'Amèrica, en canvi, les dues professions, la de "planners" i la d'arquitectes "tout-court", han produït l'empobriment d'ambdues malgrat l'especialització, que ha estat reductora per als arquitectes no-urbanistes.

Ara es tracta, doncs, d'aprendre la lliçó dels darrers temps, que són ben recents, i adonar-se que la nova disciplina i professió de paisatgista (o arquitecte del paisatge, com més us plagui) pot ser també una extensió de l'antiquíssima professió d'ordenador de l'espai i de les funcions, que encara anomenem amb el nom grec que aquell poble va donar-li, ara fa gairebé tres mil-lennis. Em refereixo a l'arquitecte i a l'Arquitectura utilitzant una definició que vaig escoltar un dia a Josep $\mathrm{M}^{\mathrm{a}}$ Sostres i que m'ha sigut molt útil. 
Particularment he de dir que alguns, i jo mateix, hem dit que el nou nom de l'Urbanisme és Paisatgisme. És a dir, que no solament es tractaria d'una extensió sinó d'una ampliació progressiva i absorbent a favor del Paisatgisme, entès com a Construcció de l'Entorn. Obrim així un nou camp dins del qual queda l'antic Urbanisme (el dels espais urbans) i com a lògica conseqüència també l'Arquitectura en versió reduïda, la dels que encara creuen en la pretesa "autonomia disciplinària".

L'extensió que defensa -i per tant el viratge al Paisatgisme que constato- no és un acte gratuï. Caldrà pagar-lo amb l'esforç per assimilar nous continguts, tant en l'aspecte científic com en el de disseny. Caldrà aprendre els processos naturals que es donen en els grans espais, més enllà dels antics límits urbans. Cal aprendre la subtilitat de llurs mecanismes, per a utilitzar-los amorosament en els nous camins del Disseny del Territori.

Roberto Burle-Marx ho va fer així, no tant a partir de l'Arquitectura com de la Pintura, i va reeixir en tantes creacions com ha deixat; Forestier i Nicolau Ma Rubió ho van aconseguir des de l'Arquitectura i des de l'Urbanisme i d'ells es pot dir que van assolir la síntesi entre els tres camps amb un únic mètode i una única sensibilitat.

En els temps actuals, quan tot es globalitza sense perdre però els detalls d'identitat en aquest món modern sorgit del segle XX que aprèn a vèncer les barreres del temps i de l'espai, el viratge al Paisatgisme significa el descobriment del Paisatge com a recurs artístic, de manera que fa global la recurrència als materials expressius que troba en el que pensàvem que era només el nostre suport físic: la Terra. El Land Art ens ho demostra. M’hi detindré un moment.

Al cap i a la fi, l'espai organitzat és un ens expressiu que és apte per comunicar també allò que pertoca al camp de l'Estètica. No en tenim prou que la comunicació assolida per la Construcció de l'Entorn sigui una expressió planera, sinó que sovint ens adonem com també és àlgida, és a dir, que es porta al límit, quan mitjançant una obra l'espai creat ens comunica la Bellesa.

Alguns en dubten, o millor en dubtaven, quan l'aparició del Land Art, és a dir l'Art del Territori, ens ha convençut del que acabo de dir. Per tant i de passada, ja a final de la meva lliçó he de ressaltar la importància que ha tingut i tindrà l'estudi la practica del Land Art en aquest esforç comunitari de totes les disciplines que fins ara s'han ocupat de la Construcció de l'Entorn, totes posades sota un denominado unificador.

Per mi, no és tant la gran dimensió la que caracteritza el Land Art, sinó aquest "nou material" d'expressió aparegut que és el TOT. Què té a veure això amb el Planejament urbanístic dels arquitectes? Jo crec que molt, si ens adonem que hom aborda el tractament dels grans espais (característics de l'Urbanisme) amb idèntica mirada inquisidora (característica dels ulls de l'arquitecte). Un cop més es tracta de la recerca de la Bellesa. El viratge a la construcció global de l'Entorn no ens nega aquesta possibilitat; i encara més, ens exigeix fer-la palesa, en un treball que alguns anomenen tècnic però que és eminentment artístic.
Fins aquí, la meva lliçó. Em queda, però, donar-vos gracies per haver estat aquí, per haver-me escoltat, per haver estat tan amables i atents.

Institucionalment, he de donar gracies a l'Escola, és a dir, molt especialment a seu Director per haver-me encomanat aquesta lliçó. Però també gracies als professors de la Casa i als del meu Departament, perquè si és cert que un professor forma alumnes, puc dir que en el meu cas els alumnes també van formar, poc o molt, aquest professor que sóc. Això va per tots vosaltres, actuals professors, perquè per fortuna meva la quasi totalitat heu estat abans alumnes meus. Gràcies a tots.

Barcelona, 23 de maig de 1996

Addenda: Els possibles interessats en els temes esbossats avui, poden recórrer a altres articles meus, en els que directament o indirecta ja havia encetat la qüestió debatuda. Són aquests:

M. RIBAS I PIERA, "The City versus Business, or better the business against Cities?”, Ed. Fifth Conference on Business Ethics, EBEN, Paris 1992.

M. RIBAS I PIERA, "L'Urbanisme i els Urbanismes en el llindar del segle. Panorama de les Arts i de les Ciències de l'espai humanitzat", a Arxius de les Seccions de Ciències, n 100, Ed. Institut d'Estudis Catalans, Barcelona agost de 1993 (publicat, desembre de 1995).

M. RIBAS I PIERA, "El viraje al Paisajismo. Historia de una docencia" a Ciudades, $\mathrm{n}^{\circ}$ 2, Ed. Instituto de Urbanística de la Universidad de Valladolid, maig de 1994 (publicat, desembre de 1994).

M. RIBAS I PIERA, "Nous horitzons per al Planejament urbanístic: El viratge al Paisatgisme”, conferencia a Castelló de la Plana, març 1995 (Fundació Ausiàs March, de Valencia), inèdit.

M. RIBAS I PIERA, "Dissegnare lo spazio, oggi”, Facoltà di Architettura, Ferrara, abril 1995 . 